Article

\title{
The Engineering Properties and Microscopic Characteristics of High-Liquid-Limit Soil Improved with Lignin
}

\author{
Xianghui Kong ${ }^{1, *(\mathbb{D})}$, Gaoqiang Wang ${ }^{1}$, Yunpeng Liang ${ }^{1}$, Zhibin Zhang $^{2}$ and Shuai Cui ${ }^{1}$ \\ 1 School of Transportation Engineering, Shandong Jianzhu University, Jinan 250101, China; \\ wanggq97@163.com (G.W.); liangyunpeng99@163.com (Y.L.); dacuishuai3@163.com (S.C.) \\ 2 School of Municipal \& Environmental Engineering, Shandong Jianzhu University, Jinan 250101, China; \\ zhangzhibinzzb@sdjzu.edu.cn \\ * Correspondence: kongxh@sdjzu.edu.cn
}

check for updates

Citation: Kong, X.; Wang, G.; Liang, Y.; Zhang, Z.; Cui, S. The Engineering Properties and Microscopic Characteristics of High-Liquid-Limit Soil Improved with Lignin. Coatings 2022, 12, 268. https://doi.org/ 10.3390 /coatings12020268

Academic Editor: Manuel

Miguel Jordan-Vidal

Received: 21 December 2021

Accepted: 15 February 2022

Published: 17 February 2022

Publisher's Note: MDPI stays neutral with regard to jurisdictional claims in published maps and institutional affiliations.

Copyright: (C) 2022 by the authors. Licensee MDPI, Basel, Switzerland. This article is an open access article distributed under the terms and conditions of the Creative Commons Attribution (CC BY) license (https:// creativecommons.org/licenses/by/ $4.0 /)$.
Abstract: To improve the engineering performance of high-liquid-limit soil, lignin, a by-product of the papermaking industry, was used. First, the influence of lignin content and curing age on the physicochemical and mechanical properties of the improved soil was determined by carrying out $\mathrm{pH}$, Atterberg limits, heavy compaction, unconfined compressive strength (UCS), California bearing ratio (CBR), and resilience modulus tests. Secondly, microscopic images obtained by scanning electron microscopy (SEM) were analyzed. The characteristic and evolution rules of the microstructure were expounded for the improved soil. Finally, combining SEM with energy-dispersive spectroscopy (EDS) and Fourier transform infrared spectroscopy (FTIR) analysis, the mechanism of lignin improvement on high-liquid-limit clay is discussed from the perspective of molecular structure. The results showed that the $\mathrm{pH}$ value of lignin-improved soil was much lower than that of quicklime-improved soil, which were 7.0 and 11.7, respectively. When the lignin content was $3 \%$, the dry density and mechanical indexes (UCS, CBR, and resilience modulus) of the improved soil all showed the maximum values. From the perspective of microstructure, the connection between soil particles was strengthened through the wrapping and filling of the flocculent cementing materials produced by lignin. The improvement mechanism of lignin on soil was the combined result of ion exchange, hydrogen bonding, covalent bonding, and electrostatic attraction.

Keywords: lignin; high-liquid-limit soil; soil improvement; engineering properties; microscopic characteristics

\section{Introduction}

High-liquid-limit soil has poor compaction, uneven gradation distribution, and unique characteristics such as high liquid limit, high plasticity index, and high water content, so it is regarded as a bad soil in engineering geology [1]. If used as subgrade filling, it can easily cause uneven settlement, cracking, sliding, and other engineering problems, so highliquid-limit soil cannot be directly applied to subgrade filling [2,3]. At present, traditional stabilizers such as cement, lime, and fly ash are used to improve high-liquid-limit soil used in engineering [4-6]. These stabilizers have a series of physical and chemical reactions with soil particles. The engineering performance of the soil is improved by changing the particle composition and mineral components.

However, traditional stabilizers also have some negative effects. For example, the strong alkali environment formed by inorganic stabilizers will pollute the surrounding soil and groundwater [7]. Most of the improved soil is brittle, which is unfavorable for the stability of the subgrade under traffic loading [8]. Furthermore, the production of cement and lime will not only consume a large amount of limestone, clay, electric energy, and heat energy but also discharge harmful substances such as $\mathrm{CO}_{2}, \mathrm{SO}_{2}$, and dust that affect air quality $[9,10]$. Therefore, with rising environmental concerns, it is particularly important to find a new type of soil stabilizer that is both economic and environmentally friendly [11-13]. 
Related research believes that using biomass waste or by-products as soil stabilizers is an excellent way to deal with this problem [14-17].

Lignin is the most abundant biopolymer on Earth after cellulose [18]. At present, lignin is mainly produced as a by-product of the paper and wood industries, and ethanol production [19]. According to statistics, the annual production of lignin from different biomass separation processes is about 70 million tons [20], and the Chinese paper industry produces about 50 million tons of lignin by-products every year [12]. Lignin contains a variety of active functional groups, such as methoxyl, phenolic hydroxyl, and benzyl alcohol groups, with certain binding properties [21]. To reduce the environmentally unfriendly volumes of fine particles, Uwaoma et al. [22] used lignin as an agglomerating agent to bind coal fines. Some scholars have explored its application in the improvement of poor soils and achieved a series of research results [23].

Santoni et al. [24] and Tingle et al. [25] adopted lignin as a stabilizer to treat silt and clay, respectively, and found that the compressive strength and water stability of ligninimproved soil were significantly enhanced. Ceylan et al. [26] studied the influence of climatic conditions on lignin-improved soil and natural soil, and the results showed that lignin-improved soil had a better pavement performance under different climatic conditions compared with natural subgrade soil. Through dynamic triaxial tests, Chen et al. [27] found that the addition of lignin can prolong the service life of sandy silt subgrade under cyclic loading. Indraratna et al. [28] used a crack simulation device to research the erosion resistance of improved silt, and the results showed that the erosion resistance of ligninimproved soil was better than that of cement-improved soil under the same critical shear stress. Vinod et al. [29] also found that the erosion resistance of erodible soil treated with lignin was significantly improved.

Kim et al. [30] considered the influence of lignin content, curing time, and water content on the solidification effect, and concluded that lignin is an environmentally friendly stabilizer with good application prospects. Zhang et al. [31-33] carried out systematic research on lignin-improved silt and discussed the physical and mechanical properties, thermal properties, durability, and micro-mechanisms of the improved soil. Furthermore, a field pavement performance test and environmental impact assessment were carried out. It was concluded that lignin could significantly improve the engineering properties of silt, which had good engineering application value [34]. He et al. [35] contrastively analyzed the engineering properties of loess improved with calcium lignosulfonate and sodium lignosulfonate and then concluded that calcium lignosulfonate could effectively improve the mechanical properties of loess. Hou et al. [36] also reached the same conclusion and speculated that calcium lignosulfonate could react with clay minerals in loess to make the soil structure denser. In addition, the researchers found a common phenomenon that the lignin content has a greater impact on the mechanical properties of the improved soil. However, the mechanical properties of the improved soil will gradually decrease when the lignin content is more than a certain amount, which is different from traditional stabilizers such as cement and lime [32,37-39].

In conclusion, lignin has an obvious improvement effect when solidifying silt, clayey silt, loess, dredged soil, and expansive soil, but there are few reports on the improvement of high-liquid-limit soil. Moreover, most of the existing research is based on alkaline sodium lignosulfonate, and there are few reports on the effect of weakly acidic calcium lignosulfonate on soil improvement. As a new stabilizer, it is of great significance to clarify the effect and mechanism of lignin in improving high-liquid-limit soil for expanding its application range.

In this study, lignin was used to improve high-liquid-limit soil, and a series of physicochemical and mechanical tests were carried out to evaluate its improvement effect. Considering that the macroscopic engineering properties of soil are affected by its microstructure to some extent, microscopic images of the improved soil were obtained by scanning electron microscopy (SEM), and the influence of lignin content on the soil microstructure was analyzed. Combining SEM with energy-dispersive spectroscopy (EDS) and Fourier 
transform infrared spectroscopy (FTIR), the chemical composition of the lignin-improved soil was analyzed. Based on the composition, the improvement mechanism of lignin on high-liquid-limit soil is discussed from the perspective of molecular structure.

\section{Materials and Methods}

\subsection{Materials}

The soil samples were extracted from a highway widening project site in Shandong Province, China. The basic physical properties of the tested soil are presented in Table 1. The grain size of the soil through a $2 \mathrm{~mm}$ sieve was tested by a laser granularity analyzer, and its distribution is shown in Figure 1. This soil is classified as high-liquid-limit clay with poor grade according to engineering classification standards [40]. The lignin used in this study was calcium lignosulphonate, which is a by-product of wood pulping using an acid method, and it was in brown powder form, as shown in Figure 2. The lignin content was about $60 \%-65 \%$. It had a slight aromatic odor and was easily soluble in water. The $\mathrm{pH}$ value of an aqueous solution with a mass ratio of lignin to water of 1:5 is 5.4. In order to compare the influence of the improved soil on $\mathrm{pH}$ value, quicklime was selected as the traditional soil stabilizer, with a $\mathrm{pH}$ of 12.8 .

Table 1. Basic properties of the natural soil.

\begin{tabular}{cc}
\hline Property & Value \\
\hline Natural water content $(\%)$ & 23.6 \\
Liquid limit $(\%)$ & 51.31 \\
Plastic limit $(\%)$ & 24.71 \\
Plasticity index & 26.6 \\
Clay $(<0.002 \mathrm{~mm})(\%)$ & 31.2 \\
Silt $(0.002-0.075 \mathrm{~mm})(\%)$ & 58.7 \\
Sand $(0.075-2 \mathrm{~mm})(\%)$ & 10.1 \\
Maximum dry density $\left(\mathrm{g} / \mathrm{cm}^{3}\right)$ & 1.77 \\
Optimal water content $(\%)$ & 16.67 \\
pH & 8.0 \\
\hline
\end{tabular}

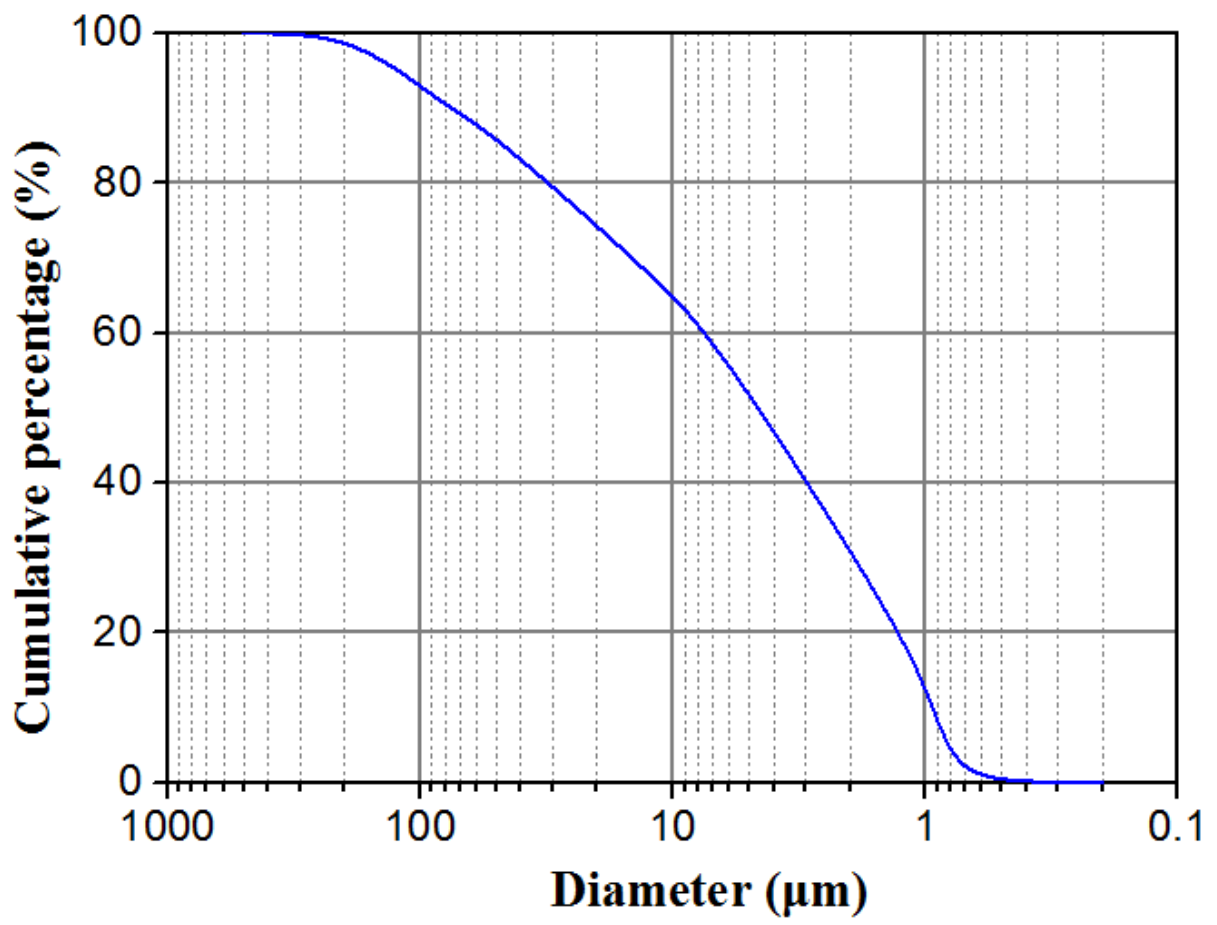

Figure 1. Grain size distribution of the natural soil. 


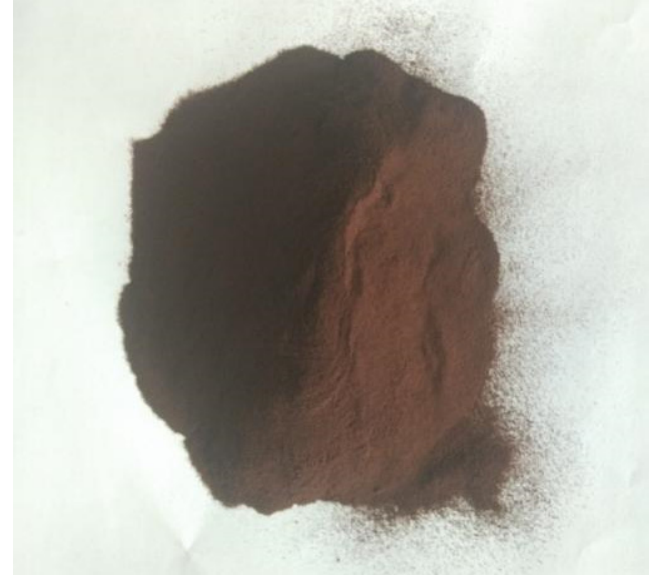

(a)

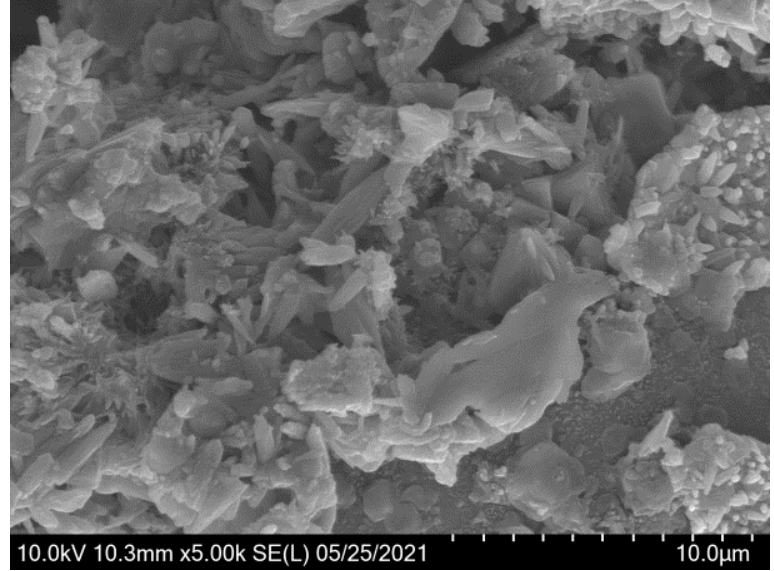

(b)

Figure 2. Calcium lignosulfonate. (a) Sample; (b) SEM image.

\subsection{Sample Preparation and Testing Program}

\subsubsection{Sample Preparation}

The soil was dried and passed through a $2 \mathrm{~mm}$ sieve to remove large particles. Lignin content was the mass percentage of dry soil. The tested soils were thoroughly mixed with different masses of lignin by hand and knives. After the compaction test, an optimal water content corresponding to different lignin contents was obtained. The required amount of water was calculated and sprayed into lignin-soil mixtures. It was mixed well with knives and sealed overnight so that the water content of each part was uniform.

\subsubsection{Testing Program}

A series of laboratory tests, including Atterberg limits, heavy compaction, unconfined compressive strength (UCS), California bearing ratio (CBR), and resilient modulus, were carried out to clarify the improvement effect of lignin on the high-liquid-limit clay and the change trend of physical and mechanical properties of the improved soil. By means of scanning electron microscopy (SEM), energy-dispersive spectroscopy (EDS), and Fourier transform infrared spectroscopy (FTIR), the microscopic characteristics and chemical structure of the improved soil were analyzed, and then the mechanism of lignin improvement was explored. In addition, in order to evaluate the influence of the modified soil on the surrounding environment, a $\mathrm{pH}$ test of the modified soil with the same content of lignin and quicklime was carried out. The specific testing program is shown in Table 2.

Table 2. Testing program.

\begin{tabular}{ccc}
\hline Test Type & Lignin Content (\%) ${ }^{\text {a }}$ & Curing Time (days) \\
\hline pH test $^{\mathrm{b}}$ & $0,1,2,3,4,5,6,9,12$ & 1,28 \\
Atterberg limits & $0,1,2,3,4,5,6$ & $1,7,28$ \\
Compaction test $^{\mathrm{d}}$ & $0,1,2,3,4,5,6$ & 1 \\
UCS test $^{\mathrm{c}}$ & $0,1,2,3,4,5,6$ & $1,7,28$ \\
CBR test $^{\mathrm{c}}$ & $0,1,2,3,4,5,6$ & $1,7,28$ \\
Resilient modulus $^{c}$ & $0,1,2,3,4,5,6$ & $1,7,28$ \\
SEM & $0,1,3,5$ & 28 \\
EDS & 0,3 & 28 \\
FTIR & 0,3 & 28 \\
\hline
\end{tabular}

a Mass ratio of lignin to dry soil. ${ }^{\mathrm{b}}$ The content of quicklime is the same as that of lignin. ${ }^{\mathrm{c}}$ The compaction degree of the sample is $98 \%$. 


\subsection{Testing Methods}

According to the test program, the improved soil samples with different lignin content were prepared first, and then the specimens for different types of tests were made. In addition to SEM, EDS, and FTIR tests, other types of tests were carried out as per JTG E40-2007 [40]. For UCS, CBR, and resilient modulus tests, the moisture content of the specimen was the optimal water content under the current lignin content, and the average values of three specimens were taken as the results.

\subsection{1. $\mathrm{pH}$ Test}

The dried soil sample was crushed and then passed through a $2 \mathrm{~mm}$ sieve. An amount of $10 \mathrm{~g}$ of the soil sample under the sieve was taken and mixed evenly with $50 \mathrm{~mL}$ of distilled water, and then the $\mathrm{pH}$ value was tested with an acidity meter (PHS-3C, Shanghai Yueping company, Shanghai, China).

\subsubsection{Atterberg Limits Test}

The dried soil sample was ground and then passed through a $0.5 \mathrm{~mm}$ sieve. An amount of $200 \mathrm{~g}$ of soil under the sieve was taken and distilled water was added and stirred. The water content of the soil sample was controlled in the liquid limit, plastic limit, and the intermediate state between the two.

\subsubsection{Compaction Test}

Five soil samples were prepared by increasing the water content by $2.5 \%$, mixing and putting into plastic bags, and sealing overnight. Each sample was compacted into 5 layers, and each layer was "brushed" after compaction.

\subsubsection{UCS Test}

The UCS test adopted cylindrical specimens with a $39.1 \mathrm{~mm}$ diameter and an $80 \mathrm{~mm}$ height. Molded specimens were wrapped in plastic bags and put into a standard curing box (temperature $20 \pm 3{ }^{\circ} \mathrm{C}$, relative humidity $\geq 95 \%$ ). When the specimen had reached its curing age, the displacement-controlled UCS tester was used for testing.

\subsubsection{CBR Test}

A cylinder with a $152 \mathrm{~mm}$ diameter and a $170 \mathrm{~mm}$ height was used according to heavy II-2 compaction standards. After soaking in water for 4 days and nights, the specimens were placed on the pavement material strength tester for the penetration test.

\subsubsection{Resilient Modulus Test}

The test was measured according to the load-bearing plate method, and a cylinder with a $152 \mathrm{~mm}$ diameter and a $170 \mathrm{~mm}$ height was used. First, the maximum unit pressure of $203.6 \mathrm{kPa}$ was used for pre-pressing twice, and the loading and unloading time of each time was $1 \mathrm{~min}$. Then, the maximum unit pressure was divided into 5 parts; the unit pressure was $25.5,50.9,101.8,152.7$, and $203.6 \mathrm{kPa}$ as the loading pressure of each stage.

\subsubsection{SEM/EDS Test}

The samples were taken from the undamaged part of the specimen section after the $28 \mathrm{~d}$ UCS test and cut into small cuboids with dimensions of $10 \mathrm{~mm} \times 5 \mathrm{~mm} \times 5 \mathrm{~mm}$. The specimen was freeze-dried to remove moisture and then broken off, and a small fragment with a clean fracture surface was placed on the copper base. After gold spraying, the copper plate was placed in the scanner. The vacuum was first pumped, and then a field emission scanning electron microscope (JSM-7610F, JEOL, Tokyo, Japan) of Japanese electronics was used for the scanning test. 


\subsubsection{FTIR Test}

About $50 \mathrm{~g}$ of soil sample was removed from the specimen after the 28 days UCS test, and it was air-dried and passed through a $0.15 \mathrm{~mm}$ sieve. The NIXUS870 infrared spectrometer (NEXUS870, NICOLET, Waltham, MA, USA) was used for testing, and a practical approach was adopted to determine functional groups [41].

\section{Results and Discussion}

\subsection{Physicochemical Tests}

\subsection{1. $\mathrm{pH}$ Value}

Figure 3 shows the relationship between the $\mathrm{pH}$ value of the improved soil and the content of the stabilizer (lignin and quicklime). With the increase in stabilizer content, the $\mathrm{pH}$ value of lignin-improved soil first decreases and then basically remains unchanged, while the $\mathrm{pH}$ value of quicklime-improved soil first increases and then stabilizes. When the lignin content is less than $3 \%$, the $\mathrm{pH}$ value of the lignin-improved soil shows a linear decline with the increase in lignin. Subsequently, the $\mathrm{pH}$ value stabilizes at about 7.0 when the lignin content continues to increase. With the increase in quicklime content, the $\mathrm{pH}$ value of the quicklime-improved soil increases gradually. However, the $\mathrm{pH}$ value stabilizes at about 11.7 when the content is more than $6 \%$. The curing time has little effect on the $\mathrm{pH}$ value of lignin-improved soil, while the $\mathrm{pH}$ value of quicklime-improved soil shows a slightly lower curve with the increase in curing time. It can be concluded that lignin can make high-liquid-limit clay develop toward a $\mathrm{pH}$ that is more conducive to the growth of vegetation. Compared with quicklime-improved soil, lignin-improved soil has obvious advantages for the ecological environment.

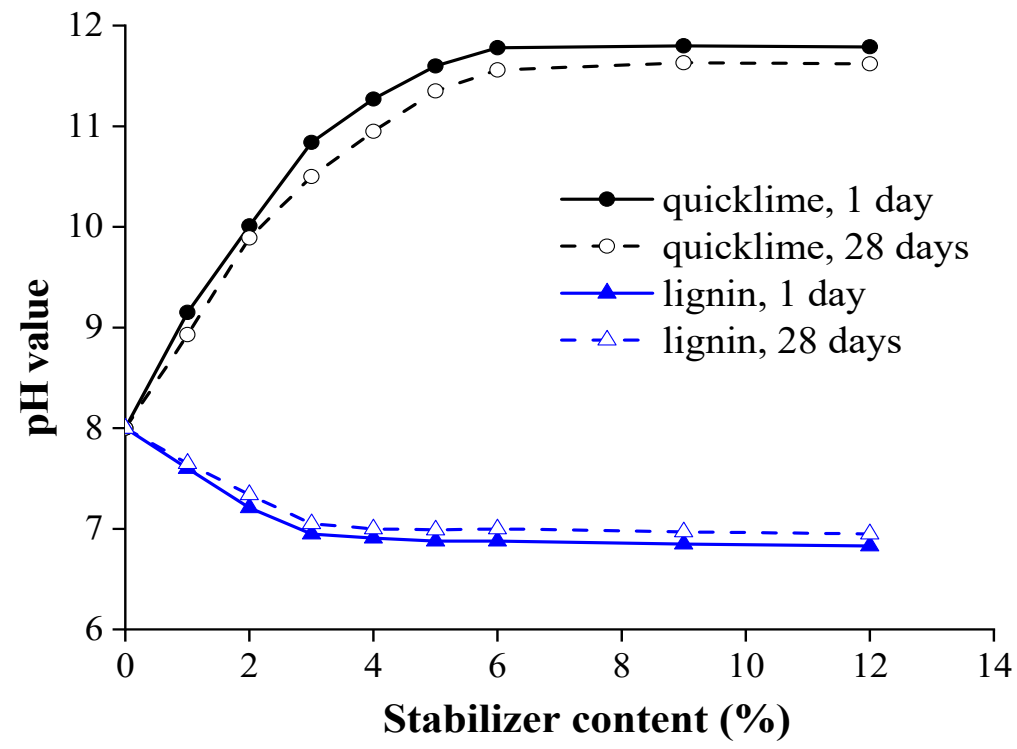

Figure 3. $\mathrm{pH}$ variations of improved soils with different stabilizer contents.

\subsubsection{Atterberg Limits}

The variations in liquid limit (LL), plastic limit (PL), and plasticity index (PI) of the improved soil with lignin content are shown in Figure 4. At different curing ages, the relationship between the three indexes (LL, PL, and PI) of the improved soil and lignin content is basically consistent. With the growth of curing age, the three indexes all decline in different degrees. When the lignin content increases from 0 to $3 \%$, the LL, PL, and PI decrease continuously. However, when the lignin content exceeds $3 \%$, the three indexes present an increasing trend with the increase in lignin content. The above laws of change are obvious in the LL and PI. When lignin content is 3\%, the three indexes of the improved soil are at a minimum. Compared with the untreated soil, the LL, PL, and PI of $3 \%$ ligninimproved soil at 1 day of age decrease by $14 \%, 5 \%$, and $22 \%$, respectively. At 7 days of 
age, the three indexes decrease by $15 \%, 7 \%$, and $23 \%$, respectively. At 28 days of age, they decrease by $17 \%, 9 \%$, and $25 \%$, respectively.

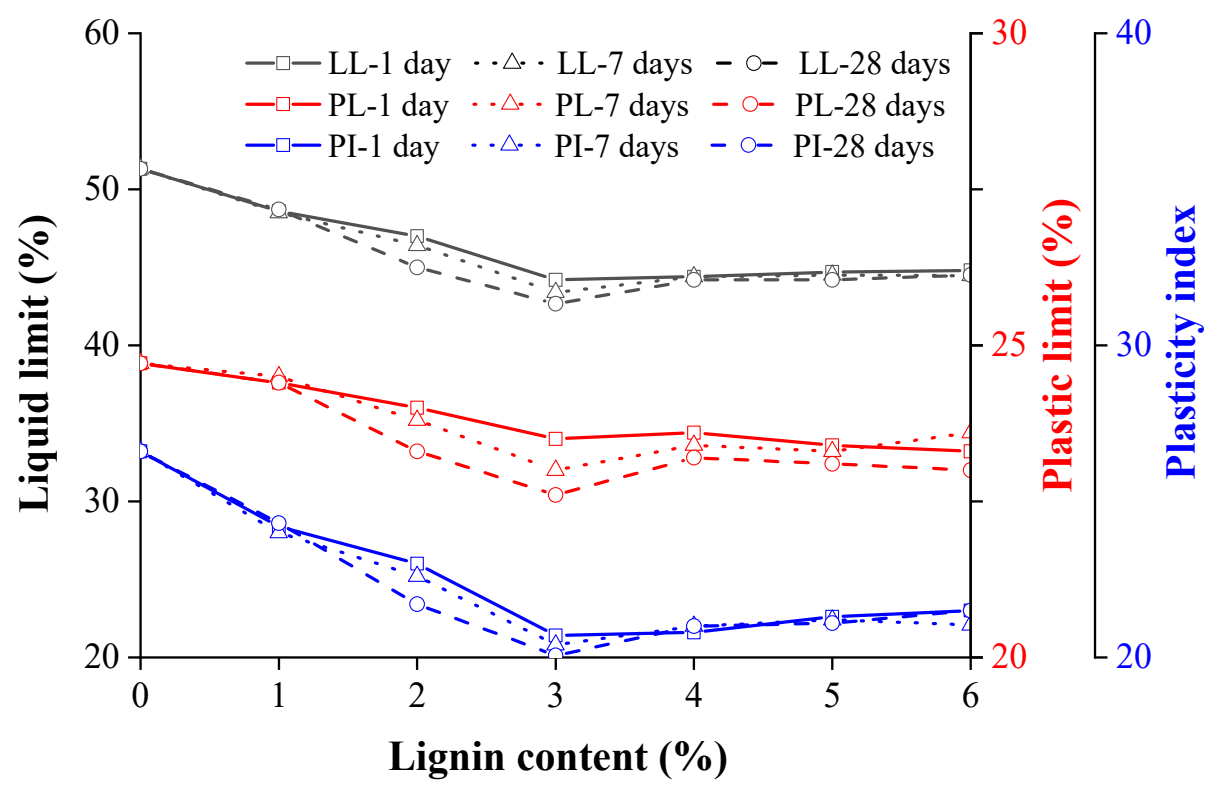

Figure 4. Atterberg limits of the improved soil with different lignin contents and curing ages.

The indexes of Atterberg limits are closely related to soil particle size, ion concentration in the pore fluid, $\mathrm{pH}$ value, and mineral composition [42]. First, lignin adheres to the surface of the soil particles, which can increase the particle size. The cementing materials formed by lignin and mineral components can also fill the soil pores and reduce the specific surface area of the soil particles. Secondly, lignin hydrolyzes in the pore solution to produce $\mathrm{H}^{+}$, and the increased positively charged ions can neutralize the negative charges on the surface of some soil particles, thus thinning the thickness of the double electric layer between the soil particles [36]. In addition, the lignin used in this study was weakly acidic. The $\mathrm{pH}$ value of the improved soil decreases with the increase in lignin, and the decrease in $\mathrm{pH}$ value will also affect the affinity of soil particles to water. These three processes can reduce the bound water content in the improved soil. However, when lignin content exceeds 3\%, the excess lignin exists in the improved soil in a free state. Lignin contains some hydrophilic groups, such as the sulfonic acid group and hydroxyl group, which can increase the content of bound water in the improved soil.

\subsubsection{Compaction Characteristics}

The maximum dry density $\left(\rho_{d, \max }\right)$ is the peak point on the relation curve between dry density and moisture content. The optimal water content $\left(\omega_{\text {opt }}\right)$ is the water content corresponding to the $\rho_{d, \max }$ of the soil. The compaction test results of the lignin-improved soil are shown in Figure 5. As can be seen from Figure 5a, when lignin content increases from 0 to $3 \%$, the compaction curve continues rising and moves to the left, indicating that the $\rho_{d, \max }$ of the improved soil continues increasing while the $\omega_{\text {opt }}$ continues decreasing. This feature is more intuitively reflected in Figure $5 \mathrm{~b}$. When the lignin content increases from $3 \%$ to $6 \%$, the $\rho_{d, \max }$ shows a downward trend, that is, the maximum $\rho_{d, \max }$ is found at $3 \%$ lignin content, reaching $1.786 \mathrm{~g} / \mathrm{cm}^{3}$. In general, the $\rho_{d, \max }$ of the improved soil with different lignin content is not significantly different; the $\rho_{d, \max }$ at $3 \%$ content increases by $0.9 \%$ compared with that of untreated soil. 


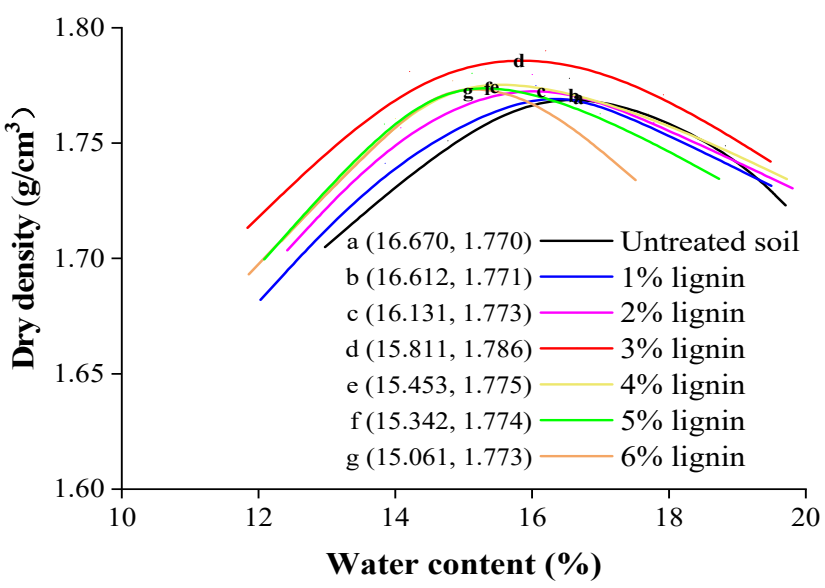

(a)

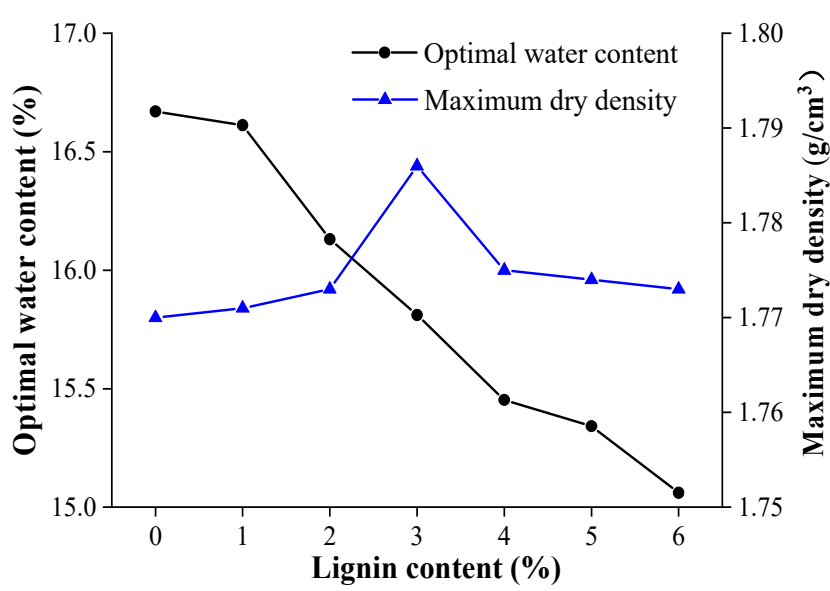

(b)

Figure 5. Compaction test results. (a) Compaction curve; (b) effect of lignin on compaction characteristics.

The effect of lignin on the $\rho_{d, \max }$ of the improved soil can be considered from two aspects: one is to fill the pores between soil particles; the other is that the density of lignin is less than that of soil. The $\rho_{d, \max }$ reaches a maximum at $3 \%$ lignin content, indicating that the intergranular pores of the soil were filled most effectively under this state. As the lignin content continues to increase, a large amount of free lignin weakens the bond between soil particles, which results in the decrease in the $\rho_{d, \max }$. The optimal water content decreases with the increase in lignin. This is due to the ability of cementing materials formed by lignin and clay minerals to wrap soil particles. The outer wrapping effect reduces the affinity of soil to water.

\subsection{Mechanical Properties}

The effects of lignin content and curing age on the UCS, CBR, and resilient modulus of the improved soil are shown in Figure 6. With the increase in lignin, the three mechanical indexes all show a trend of first increasing and then decreasing, and all reach a maximum value at $3 \%$ content. Compared with the untreated soil, the UCS, CBR, and resilient modulus of the $3 \%$ lignin-improved soil increase by $92 \%, 496 \%$, and $321 \%$, respectively, at the curing age of 28 days.

When the lignin content exceeds a certain value, the three mechanical indexes decrease with the increase of lignin. Other researchers have obtained similar results when using lignin to improve low-liquid-limit clay, silty sand, and silt [31,37-39]. For example, Zhang et al. [31] found that when the lignin content exceeded $12 \%$, the UCS, CBR, and resilience modulus of the improved soil showed a decreasing trend.

The main reason for this phenomenon is that the cementing materials formed by lignin and clay minerals can fill the pores of the soil and thus strengthen it. However, the continuous increase in lignin does not lead to the continuous enhancement of the cementing strength. In this study, when the lignin content exceeds $3 \%$, the improved soil is filled with quite a lot of lignin particles. Due to the good adhesion and chelation, lignin will preferentially combine with itself to form macromolecules, which weakens its role in cementing particles and filling pores, thus causing the decreases in the mechanical indexes of the improved soil. 


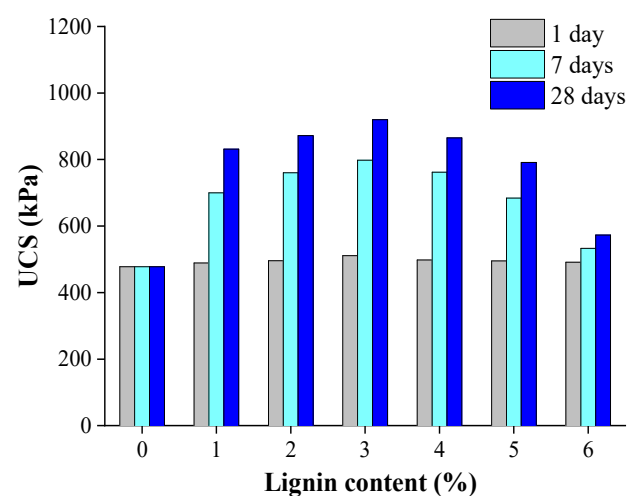

(a)

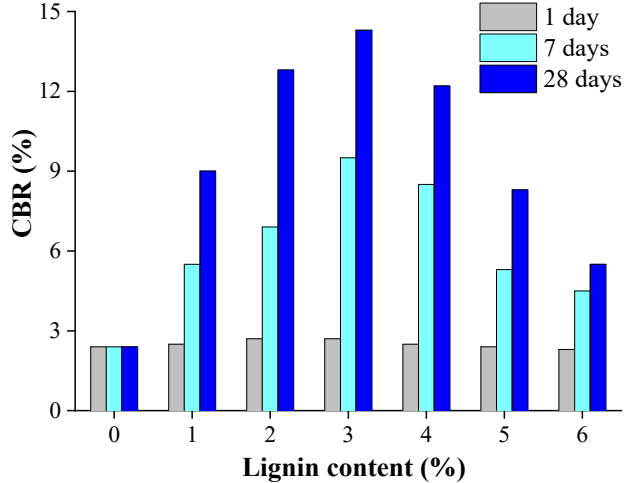

(b)

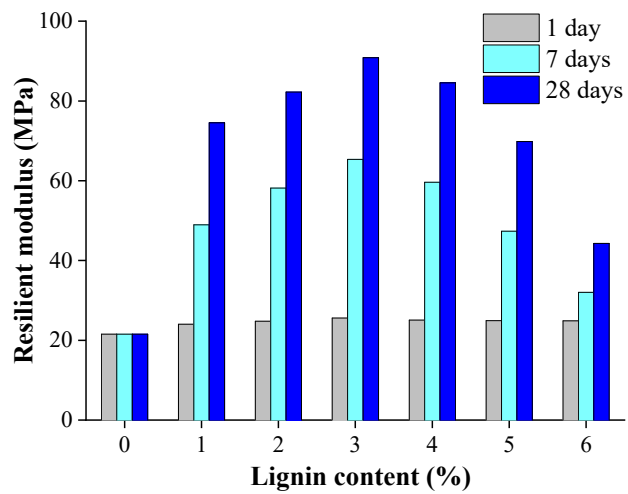

(c)

Figure 6. Mechanical properties of lignin-improved soil. (a) UCS; (b) CBR; (c) resilient modulus.

It can also be seen from Figure 6 that the curing age has a great influence on the mechanical indexes of the improved soil. The mechanical properties of the improved soil with different lignin content show little difference at 1 day of age, while at 7 and 28 days of age, the difference becomes particularly obvious. For the $3 \%$ lignin-improved soil, compared with 1 day of age, the UCS at 7 and 28 days of age increases by $56 \%$ and $80 \%$, the CBR increases by $252 \%$, and $430 \%$, and the resilient modulus increases by $155 \%$ and $255 \%$.

\subsection{Microstructure Characteristic}

Figure 7 shows the SEM images (1000 times magnified) for the improved soil samples with different lignin content. It can be seen from Figure 7a that the untreated soil is mainly composed of a dense clay matrix. There are fewer connections between the particles but more pores, resulting in a loose soil structure. When the lignin content is $1 \%$ (Figure $7 \mathrm{~b}$ ), flocculent aggregates (cementing materials) are found on the surface of the soil particles and in the tiny pores of the sample, but not in the large pores. When the lignin content is $3 \%$ (Figure $7 \mathrm{c}$ ), cementing materials increase significantly, and both large and small pores are filled with them. Figure $7 \mathrm{~d}$ shows the microstructure of $5 \%$ lignin-improved soil, which is similar to that of $1 \%$ lignin content, but the bonding effect between aggregates and particles is weakened. When lignin is added to the geopolymer, the higher lignin content also results in a porous morphology of the composites [43]. The microstructure analysis of the improved soil shows that lignin and soil minerals form cementing materials. Some types of cement are attached to the surface of soil particles and have an encapsulation effect on the particles, while other types of cement are aggregated between the pores of the particles. In addition to filling the pores, the cementing materials can further strengthen the bonds between the particles wrapped by them, making a previously loose soil structure more compact and stable. When lignin has been used to improve silt and expansive soil, similar cementing materials have been observed in the improved soil [32,44]. 


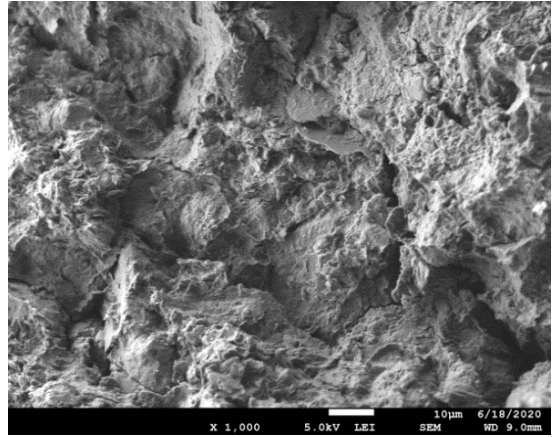

(a)

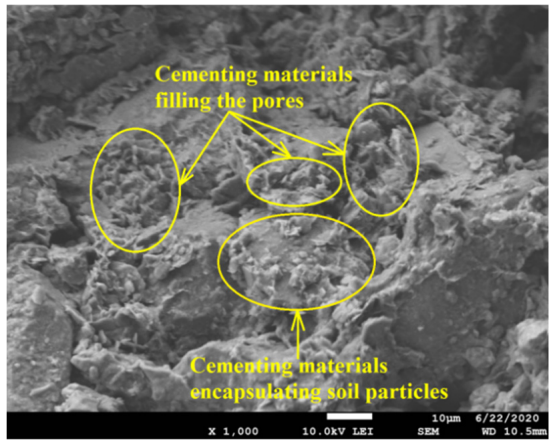

(c)

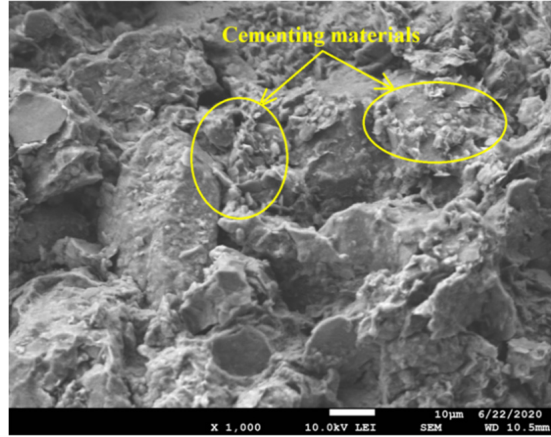

(b)

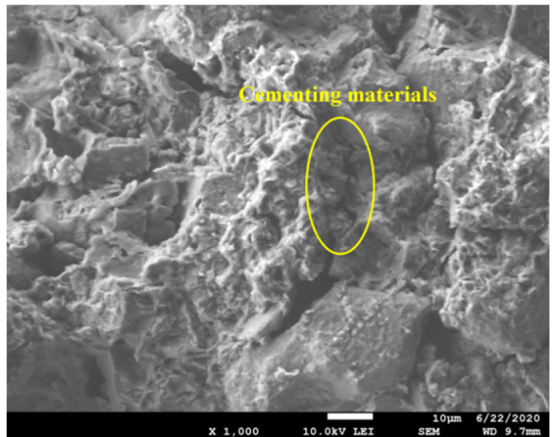

(d)

Figure 7. SEM images of the improved soil (28 days) with (a) $0 \%$, (b) $1 \%$, (c) $3 \%$, and (d) $5 \%$ lignin.

\subsection{Discussion on the Mechanism of Lignin Improvement}

Figure 8 presents the EDS analysis results of lignin, untreated soil, and 3\% ligninimproved soil. Figure 8a shows that the main chemical elements of lignin are $\mathrm{O}, \mathrm{S}, \mathrm{Cl}$, and $\mathrm{Ca}$. Figure $8 \mathrm{~b}$ shows that the main chemical elements of the untreated soil are $\mathrm{O}, \mathrm{Mg}, \mathrm{Al}$, and Si. It can be seen from Figure $8 \mathrm{c}$ that the elements of the improved soil are the sum of the untreated soil and the lignin, indicating that no new materials are formed in the improved soil complex.

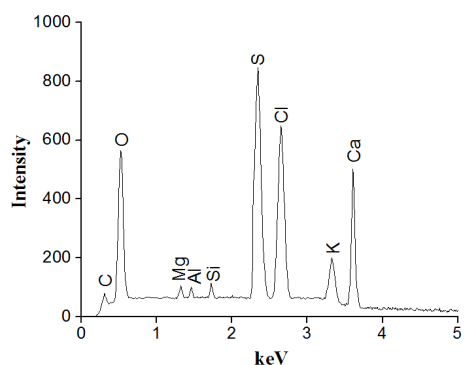

(a)

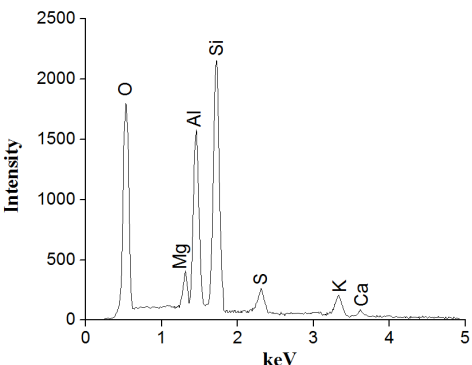

(b)

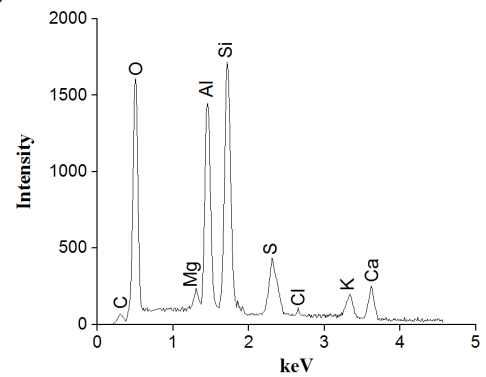

(c)

Figure 8. EDS spectra of (a) lignin, (b) untreated soil, and (c) 3\% lignin-improved soil. 
$\mathrm{Al}$ and $\mathrm{Si}$ are the basic elements in clay minerals. If the contents of Al and Si change greatly before and after treatment, it indicates that there has been a chemical alteration [44]. In this study, the weight contents of $\mathrm{Al}$ and $\mathrm{Si}$ in the untreated soil are $10.12 \%$ and $25.87 \%$, and $9.31 \%$ and $23.62 \%$ in the improved soil. The Al:Si ratio only increases from 0.391 to 0.394, suggesting negligible chemical reactions between the clay minerals and lignin.

Figure 9 shows the FTIR test results of lignin, the untreated soil, and 3\% ligninimproved soil. Figure 9a shows that lignin mainly contains a hydroxyl group $(-\mathrm{OH})$, methoxyl group $\left(-\mathrm{OCH}_{3}\right)$, methylene group $\left(-\mathrm{CH}_{2}\right)$, sulfonic group $\left(-\mathrm{SO}_{3}{ }^{-}\right)$, benzene ring $(\mathrm{C}=\mathrm{C})$, and alcohol group $(-\mathrm{C}-\mathrm{O})$. Figure $9 \mathrm{~b}$ shows that the untreated soil mainly contains $\mathrm{Al}-\mathrm{O}-\mathrm{H}$ bonds, $\mathrm{Si}-\mathrm{O}$ bonds, $\mathrm{HOH}$ bending modes, and hydroxyl groups $(-\mathrm{OH})$. It can be seen from Figure $9 \mathrm{c}$ that the functional group of lignin-improved soil is the sum of untreated soil and lignin. The difference in diffraction band number between the improved soil and the untreated soil is $600-1800 \mathrm{~cm}^{-1}$, which is consistent with the band number of lignin functional groups. It is inferred that ionic bonds are formed between lignin and soil minerals.

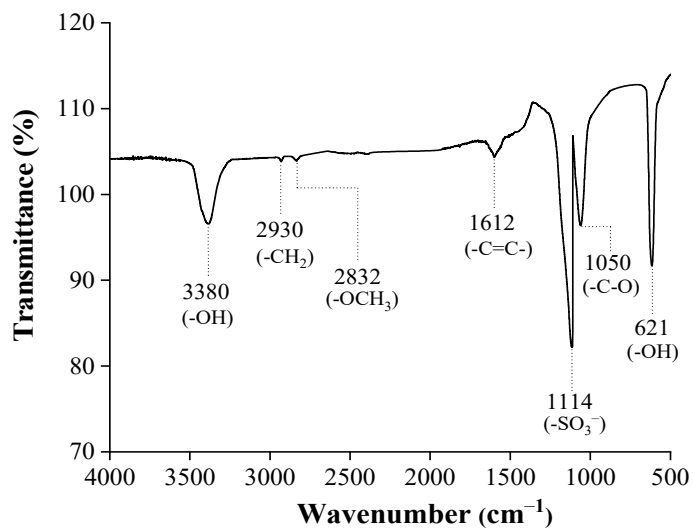

(a)

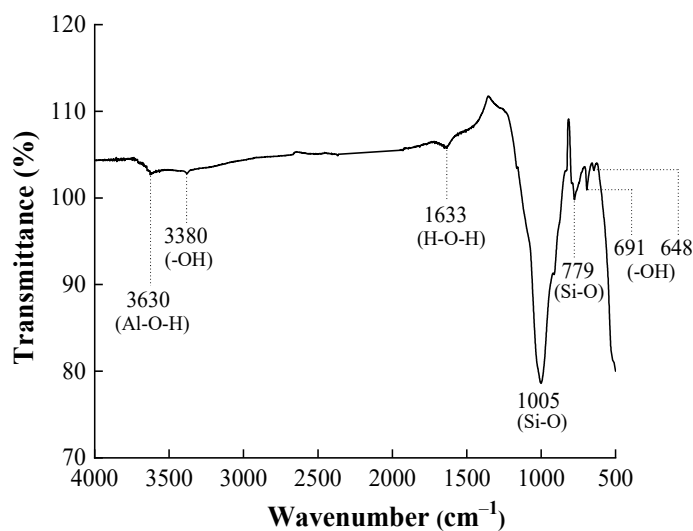

(b)

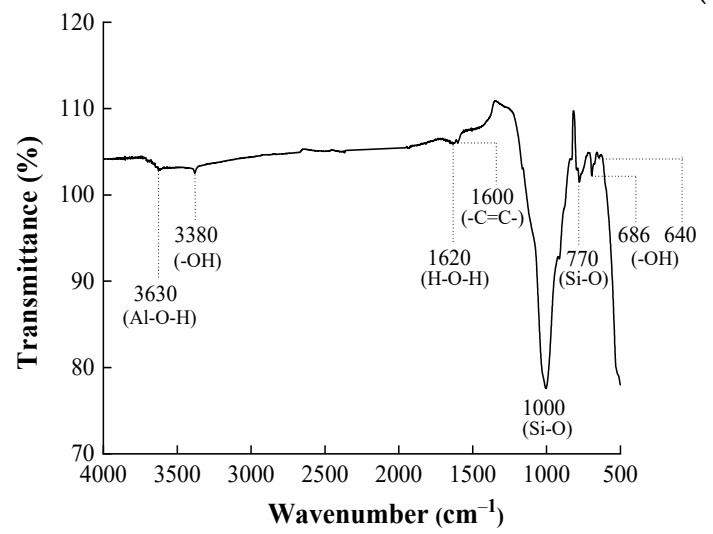

(c)

Figure 9. FTIR spectra of (a) lignin, (b) untreated soil, and (c) 3\% lignin-improved soil.

Combining the FTIR test results (Figure 9a) with the main components of lignin (Figure 8a), the chemical structure formula of calcium lignosulfonate can be obtained, as shown in Figure 10. It can be seen that the basic chemical structure of lignin has a benzene ring connected with a hydroxyl group, methoxyl group, sulfonic group, and other functional groups. Many benzene rings are linked together to form a complex polymer, which can combine with $\mathrm{Na}^{+}, \mathrm{Ca}^{2+}, \mathrm{Mg}^{2+}$, and other cations, or form covalent bonds with metal ions. 


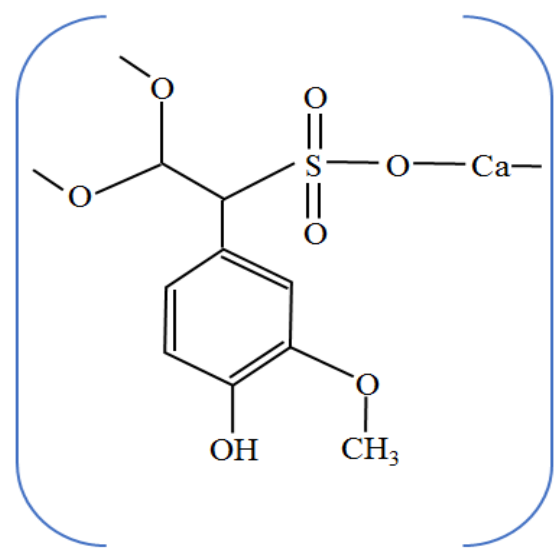

Figure 10. Molecular structure of calcium lignosulfonate.

Based on the analysis of the molecular structure of lignin, the improvement mechanism of lignin on high-liquid-limit soil is discussed, as shown in Figure 11. $\mathrm{Ca}^{2+}$ in lignin can be exchanged with a cation such as $\mathrm{Na}^{+}$and $\mathrm{Mg}^{2+}$ in soil, which was also mentioned by Zhang et al. [32]. For clayey soils, cation exchange plays a major role in the stabilization mechanism [39]. As lignin is embedded into the mineral lattice, it first displaces water in the outer sphere of the monovalent and divalent coordination cations. Next, one part of lignin forms hydrogen bonds directly with the coordination water, and the other part forms covalent bonds with cations in the clay minerals. Under the combined action of ion exchange, hydrogen bonding, and covalent bonding, lignin is adsorbed to the surface of clay minerals to form polymers with similar cementing properties, forming a coating on the soil particles. In addition, it can be seen from Figure 11 that there are many cationic ends in the molecular structure of the polymer. Therefore, the polymer is positively charged. The clay particles have a certain amount of negative charge on surface, which is interactively adsorbed with the polymer under electrostatic gravitational force. Furthermore, part of the negative charge on the surface of the soil particles is neutralized, which reduces the thickness of the double electric layer and the spacing between the soil particles accordingly.

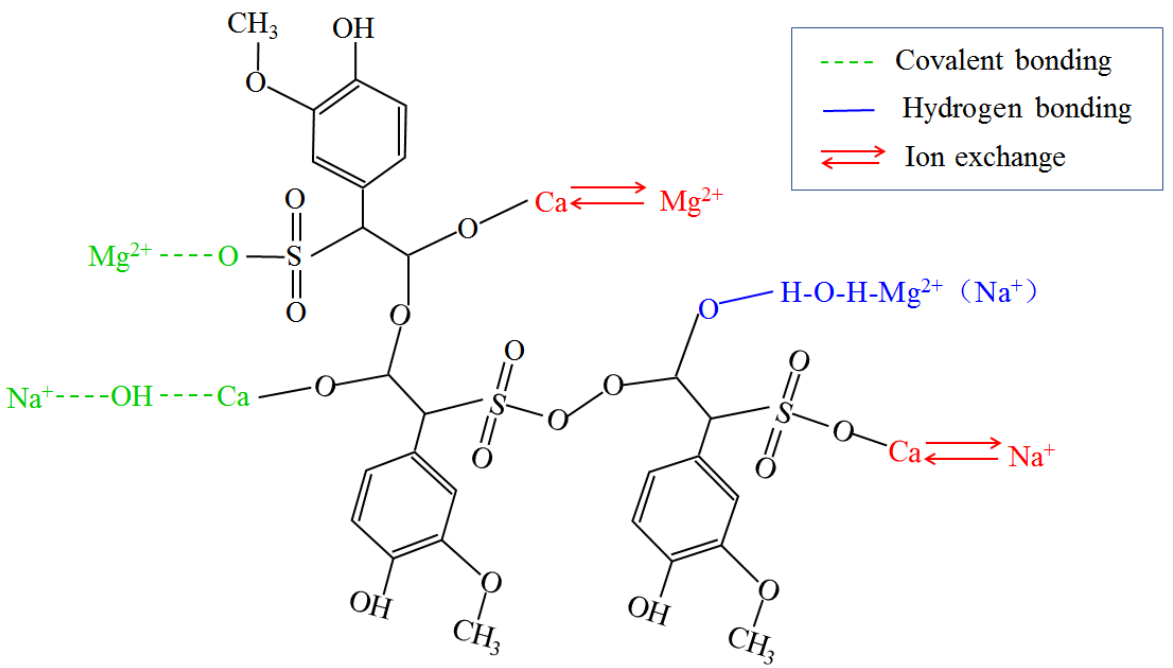

Figure 11. Improvement mechanism of lignin on soil.

In short, the main improvement mechanism of lignin on soil can be explained as follows. Through ion exchange, hydrogen bonding, covalent bonding, and electrostatic interaction, a polymer with cementing properties is formed by ionic bonds between lignin and clay minerals. By strengthening the bonds and filling the pores between soil particles, 
the cementing materials can enhance the grain tightness and structural stability of the improved soil.

\section{Conclusions and Outlook}

In this study, lignin was used to improve high-liquid-limit soil. A series of physicochemical tests, mechanical tests, and microscopic characteristic tests were carried out to evaluate the improvement effect of lignin. The following conclusions can be drawn:

(1) Lignin had little effect on the $\mathrm{pH}$ of the improved soil. With the increase in lignin content, the $\mathrm{pH}$ value of the improved soil decreased gradually and then stabilized at about 7.0. Compared with the traditional chemical stabilizer (quicklime), lignin has obvious advantages for the ecological environment.

(2) With the increase in lignin content, the liquid limit, plastic limit, and plasticity index of the improved soil decreased first and then increased and reached a minimum value when the lignin content was 3\%.

(3) When the lignin content was 3\%, the dry density, UCS, CBR, and resilient modulus of the improved soil all showed maximum values.

(4) The improvement mechanism of lignin on soil can be attributed to ion exchange, hydrogen bonding, covalent bonding, and electrostatic attraction. Under the combined action of the above factors, a polymer with cementing properties was formed between lignin and clay minerals, which improved the structural stability of the soil by encapsulating soil particles and filling pores and showed the enhancement of engineering properties of the soil on a macro level.

It should be noted that the conclusions reported above are only based on tests of high-liquid-limit soil, and these results may apply to similar soil types, but cannot be directly generalized to any other soil. In addition, when the lignin content exceeded $3 \%$, the mechanical indexes of the improved soil began to decrease. As for the reason the bond effect between soil particles weakened when the lignin content exceeded a certain value, due to the gap of relevant professional knowledge and lack of in-depth research, this study only generally speculated that it is caused by excessive free lignin.

In this study, SEM, EDS, and FTIR tests were used for microscopic analysis of ligninimproved soil. The SEM test observed that cementing materials were formed between lignin and soil minerals. The EDS and FTIR tests indicated that the cementing materials were not formed by chemical reaction, but by ionic bonds interaction. This discovery laid a foundation for exploring the mechanism of lignin improvement on soil. To account for the deterioration of mechanical properties due to increased lignin content, other analysis methods such as computed tomography (CT), Mercury intrusion porosimetry (MIP), and cation exchange capacity (CEC) can be performed to analyze the pore space and cation exchange of the lignin-improved soil. This is what we will study in the future.

Author Contributions: Conceptualization, X.K. and Z.Z.; methodology, G.W.; validation, G.W., Y.L., and S.C.; formal analysis, G.W.; investigation, X.K.; resources, X.K. and Z.Z.; data curation, Y.L.; writing original draft, X.K.; writing review, Z.Z.; supervision, X.K. All authors have read and agreed to the published version of the manuscript.

Funding: This research was funded by Key Research and Development Project of Shandong (grant number 2020CXGC011404); and the China Postdoctoral Science Foundation-funded project (grant number 2019M652302)

Institutional Review Board Statement: Not applicable.

Informed Consent Statement: Not applicable.

Data Availability Statement: The data presented in this study are available on request from the corresponding author.

Conflicts of Interest: The authors declare no conflict of interest. 


\section{References}

1. Lu, Z.; Fang, R.; Zhan, Y.; Yao, H. Study on the dynamic deformation of road high liquid limit subgrade soil. Adv. Civ. Eng. 2019, 2019, 4084983. [CrossRef]

2. Wang, Y.; Zhang, H.; Zhang, Z. Experimental study on mechanics and water stability of high liquid limit soil stabilized by compound stabilizer: A sustainable construction perspective. Sustainability 2021, 13, 5681. [CrossRef]

3. Wang, J.; Wu, L.; Feng, R. An experimental case study of a high-liquid-limit lateritic soil with its application in road construction. Road Mater. Pavement Des. 2017, 18, 1423-1433. [CrossRef]

4. Latifi, N.; Rashid, A.S.A.; Siddiqua, S.; Horpibulsuk, S. Micro-structural analysis of strength development in low- and high swelling clays stabilized with magnesium chloride solution-A green soil stabilizer. Appl. Clay Sci. 2015, 118, 195-206. [CrossRef]

5. Gautam, S.; Hoyos, L.R.; He, S.; Prabakar, S.; Yu, X. Chemical treatment of a highly expansive clay using a liquid ionic soil stabilizer. Geotech. Geol. Eng. 2020, 38, 4981-4993. [CrossRef]

6. Guo, Q.; Wei, M.; Du, G.; Xue, H.; Liu, S. Research on strength behavior and micro-mechanism of AMC stabilized high liquid limit clay. J. China Univ. Min. Technol. 2018, 47, 838-845.

7. Ikeagwuani, C.C.; Nwonu, D.C. Emerging trends in expansive soil stabilization: A review. J. Rock Mech. Geotech. Eng. 2019, 11, 423-440. [CrossRef]

8. Sariosseiri, F.; Muhunthan, B. Effect of cement treatment on geotechnical properties of some Washington State soils. Eng. Geol. 2009, 104, 119-125. [CrossRef]

9. Shihab, A.M.; Abbas, J.M.; Ibrahim, A.M. Effects of temperature in different initial duration time for soft clay stabilized by fly ash based geopolymer. Civ. Eng. J. 2018, 4, 2082-2096. [CrossRef]

10. Liu, S.; Zhang, T.; Cai, G.; Li, J.; Jie, D. Research progress of soil stabilization with lignin from bio-energy by-products. China J. Highw. Transp. 2014, 27, 1-10.

11. Latifi, N.; Suksun, H.; Meehan, C.L.; Abd Majid, M.Z.; Tahir, M.M.; Mohamad, E.Z. Improvement of problematic soils with biopolymer-An environmentally friendly soil stabilizer. J. Mater. Civ. Eng. 2017, 29, 04016204. [CrossRef]

12. Zhang, T.; Cai, G.; Liu, S.; Puppala, A.J. Engineering properties and microstructural characteristics of foundation silt stabilized by lignin-based industrial by-product. KSCE J. Civ. Eng. 2016, 20, 2725-2736. [CrossRef]

13. Fatehi, H.; Abtahi, S.M.; Hashemolhosseini, H.; Hejazi, S.M. A novel study on using protein based biopolymers in soil strengthening. Constr. Build. Mater. 2018, 167, 813-821. [CrossRef]

14. Kamath, M.; Prashant, S.; Kumar, M. Micro-characterisation of alkali activated paste with fly ash-GGBS-metakaolin binder system with ambient setting characteristics. Constr. Build. Mater. 2021, 277, 122323. [CrossRef]

15. Boquera, L.; Olacia, E.; Fabiani, C.; Pisello, A.L.; D’Alessandro, A.; Ubertini, F.; Cabeza, L.F. Thermo-acoustic and mechanical characterization of novel bio-based plasters: The valorisation of lignin as by-product from biomass extraction for green building applications. Constr. Build. Mater. 2021, 278, 122373. [CrossRef]

16. Mavroulidou, M. Use of waste paper sludge ash as a calcium-based stabiliser for clay soils. Waste Manag. Res. 2018, 36, 1066-1072. [CrossRef]

17. Ramdas, V.M.; Mandree, P.; Mgangira, M.; Mukaratirwa, S.; Lalloo, R.; Ramchuran, S. Review of current and future bio-based stabilisation products (enzymatic and polymeric) for road construction materials. Transp. Geotech. 2021, 27, 100458. [CrossRef]

18. Pérez, I.P.; Pasandín, A.M.R.; Pais, J.C.; Pereira, P.A.A. Use of lignin biopolymer from industrial waste as bitumen extender for asphalt mixtures. J. Clean. Prod. 2019, 220, 87-98. [CrossRef]

19. Liu, Y.; Zheng, W.; Wang, Q.; Cao, C.; Chang, M.; Rocchi, I. Evaluating sulfur-free lignin as a sustainable additive for soil improvement against frost resistance. J. Clean. Prod. 2020, 251, 119504. [CrossRef]

20. Di Matteo, L.; Bulletti, L.; Capecchi, E.; La Viola, A.; Piccinino, D.; Piscopo, V. Perspectives of using lignin as additive to improve the permeability of in-situ soils for barrier materials in landfills. Sustainability 2020, 12, 5197. [CrossRef]

21. Park, G.W.; Gong, G.; Joo, J.C.; Song, J.; Lee, J.; Lee, J.P.; Kim, H.T.; Ryu, M.H.; Sirohi, R.; Zhuang, X.; et al. Recent progress and challenges in biological degradation and biotechnological valorization of lignin as an emerging source of bioenergy: A state-of-the-art review. Renew. Sustain. Energy Rev. 2022, 157, 112025. [CrossRef]

22. Uwaoma, R.C.; Seheri, M.P.; Strydom, C.A.; Bunt, J.R.; Matjie, R.H. The influence of calcium lignosulphonate addition on non-isothermal pyrolysis and gasification of demineralized bituminous coal fines. Thermochim. Acta 2022, 707, 179096. [CrossRef]

23. Surdahl, R.W.; Woll, J.H.; Marquez, H.R. Stabilization and dust control at the Buenos Aires National Wildlife Refuge, Arizona. Transp. Res. Rec. 2007, 1, 312-321. [CrossRef]

24. Santoni, R.L.; Tingle, J.S.; Webster, S.L. Stabilization of silty sand with nontraditional additives. Transp. Res. Rec. 2002, 61-72. [CrossRef]

25. Tingle, J.S.; Santoni, R.L. Stabilization of clay soils with nontraditional additives. Transp. Res. Rec. 2003, 72-84. [CrossRef]

26. Ceylan, H.; Gopalakrishnan, K.; Kim, S. Soil Stabilization with bioenergy coproduct. Transp. Res. Rec. 2010, 130-137. [CrossRef]

27. Chen, Q.; Indraratna, B. Deformation behavior of lignosulfonate-treated sandy silt under cyclic loading. J. Geotech. Geoenvironmental Eng. 2015, 141, 06014015. [CrossRef]

28. Indraratna, B.; Muttuvel, T.; Khabbaz, H.; Armstrong, R. Predicting the erosion rate of chemically treated soil using a process simulation apparatus for internal crack erosion. J. Geotech. Geoenviron. Eng. 2008, 134, 837-844. [CrossRef]

29. Vinod, J.S.; Indraratna, B.; Al Mahamud, M.A. Stabilisation of an erodible soil using a chemical admixture. Proc. Inst. Civ. Eng. Ground Improv. 2010, 163, 43-51. [CrossRef] 
30. Kim, S.; Gopalakrishnan, K.; Ceylan, H. Moisture susceptibility of subgrade soils stabilized by lignin-based renewable energy coproduct. J. Transp. Eng. 2012, 138, 1283-1290. [CrossRef]

31. Zhang, T.; Liu, S.; Cai, G.; Li, J.; Jie, D. Experimental study on relationship between thermal and mechanical properties of treated silt by lignin. Chin. J. Geotech. Eng. 2015, 37, 1876-1885.

32. Zhang, T.; Cai, G.; Liu, S.; Liu, J.; Jie, D. Research on stabilization microcosmic mechanism of lignin based industrial by-product treated subgrade silt. Rock Soil Mech. 2016, 37, 1666-1672.

33. Zhang, T.; Liu, S.; Zhan, H.; Ma, C.; Cai, G. Durability of silty soil stabilized with recycled lignin for sustainable engineering materials. J. Clean. Prod. 2020, 248, 119293. [CrossRef]

34. Liu, S.; Zhang, T.; Cai, G. Research on technology and engineering application of silt subgrade solidified by lignin-based industrial by-product. China J. Highw. Transp. 2018, 31, 1-11.

35. He, Z.; Fan, H.; Wang, J.; Liu, G.; Wang, Z.; Yu, J. Experimental study of engineering properties of loess reinforced by lignosulfonate. Rock Soil Mech. 2017, 38, 731-739.

36. Hou, X.; Ma, W.; Li, G.; Mu, Y.; Zhou, Z.; Wang, F. Influence of lignosulfonate on mechanical properties of Lanzhou loess. Rock Soil Mech. 2017, 38, 18-26.

37. Liu, W.; Zhang, E. Compression characteristics of dredging soil solidified by lignin. J. Yangtze River Sci. Res. Institute 2017, $34,83-86$.

38. Kong, X.; Song, S.; Wang, M.; Zhao, Q. Experimental research of low liquid limit silt stabilized by lignin in the flooding area of yellow river. Geotech. Geol. Eng. 2019, 37, 5211-5217. [CrossRef]

39. Ta'negonbadi, B.; Noorzad, R. Stabilization of clayey soil using lignosulfonate. Transp. Geotech. 2017, 12, 45-55. [CrossRef]

40. Ministry of Transport of the People's Republic of China. Test Methods of Soils for Highway Engineering; JTG E40-2007; Press of China: Beijing, China, 2007.

41. Coates, J. Interpretation of infrared spectra, a practical approach. In Encyclopedia of Analytical Chemistry; Meyers, R.A., Ed.; John Wiley \& Sons, Ltd.: Chichester, UK, 2006; p. a5606.

42. Zhang, R.; Xiao, Y.; Liu, C.; Zheng, J. Control standards for degree of compaction of high liquid limit soil subgrade considering effects of adsorbed bound water. China J. Highw. Transp. 2020, 33, 32-40+50.

43. Ye, H.; Zhang, Y.; Yu, Z.; Mu, J. Effects of cellulose, hemicellulose, and lignin on the morphology and mechanical properties of metakaolin-based geopolymer. Constr. Build. Mater. 2018, 173, 10-16. [CrossRef]

44. Alazigha, D.P.; Indraratna, B.; Vinod, J.S.; Heitor, A. Mechanisms of stabilization of expansive soil with lignosulfonate admixture. Transp. Geotech. 2018, 14, 81-92. [CrossRef] 